\title{
Influence of Metakaolin in High Strength Concrete of M70 Grade for Various Temperatures and Acidic Medium
}

\author{
D.Viswanadha Varma ${ }^{1}$, G.V. Rama Rao ${ }^{2}$ \\ 1. Research Scholar, Andhra University College of Engineering, Visakhapatnam, A.P., India. \\ 2. Professor, Dept of Civil Engineering, Andhra University College of Engineering, Visakhapatnam, A.P., India.
}

\begin{abstract}
Concrete made of cement is the most adaptive material for construction purpose. Design and Preparation of such a concrete mix with good strength and durability has been always the need of the day. Use of mineral admixture in concrete mix has made a remarkable achievement in development and design of high strength concrete.

Among many mineral admixtures available, Metakaolin $(M K)$ is a mineral admixture, whose potential is not yet fully tested and only limited studies have been carried out in India on the use of MK for the development of high strength concrete. $M K$ is a supplementary cementations material derived from heat treatment of natural deposits of kaolin. MK shows high pozzolanic reactivity due to their amorphous structure and high surface area.

In this present study Metakaolin is replaced with 0, 10,15,20, 25 and $30 \%$ of cement to observe the compressive strength of M70 grade concrete. Conclusions are made from the various results and the discussions there on to identify the effect of partial replacement of cement by $M K$ in the design concrete mix. The results conclude that, the use of Metakaolin Concrete (MKC) has improved the performance of concrete under various conditions
\end{abstract}

Key words: Metakaolin, High Strength Concrete, Temperatures and Acidic Medium.

\section{Introduction}

Concrete is one of the most widely used man-made construction material in the world. Metakaolin is the cementations material used as an admixture to produce high strength concrete. Optimal quality of Metakaolin for M70 grade of concrete has been worked out, which can replace the cement in order to get better strength and durability. Also identification of the drying shrinkage and permeability characteristics of blended cement has been done. Jipingbai studied that when metakaolin is used as a partial replacement for Portland cement, tends to improve both the mechanical properties and durability of concrete. Friars and Cabrera investigated the relation between the pore size distribution and degree of hydration of metakaolin based cement pastes.

Metakaolin is the white powder of $\mathrm{Al}_{2} \mathrm{O}_{3} \cdot 2 \mathrm{SiO}_{2}$ by dehydrating kaolin $\left(\mathrm{Al}_{2} \mathrm{O}_{3} \cdot 2 \mathrm{SiO}_{3} \cdot 2 \mathrm{H}_{2} \mathrm{O}\right)$ at an appropriate temperature $\left(700-900^{\circ} \mathrm{C}\right)$. Kaolin is in a layered silicate structure, with the layers binding with each other via the Van Der Weal's bond, among which $\mathrm{OH}^{-}$is bound firmly. Kaolin, when being heated in air, may experience several structural changes, and when being heated to around $600^{\circ} \mathrm{C}$, the layered structure of kaolin is damaged due to dehydration to form a transient phase with a poor crystallinity, i.e. metakaolin. As the molecular arrangement of metakaolin is irregular in a thermodynamic metastable condition, it is cementations under an adequate excitation. With a high activity, metakaolin can be used to manufacture cementations materials and mix high-strength high-performance concrete.

\section{Methodology}

Based on the preliminary investigations carried out, the experimental investigation is planned as under. To obtain the mix proportions of OPC concrete for M70 by Entropy and Shack lock's Empirical graphs. To calculate the mix proportions with partial replacements such as $0 \%, 10 \%, 15 \%, 20 \%, 25 \%$ and $30 \%$ of Metakaolin with concrete. Preparations of testing specimens are as follows.

1. To prepare concrete specimens such as cubes $(150 \times 150 \times 150)$ for durability studies in laboratory with $0 \%, 10 \%, 15 \%, 20 \%, 25 \%$ and 30\%replacement of OPC with Metakaolin for M70 grade concrete.

2. To prepare the concrete specimens such as cubes $(150 \times 150 \times 150 \mathrm{~mm})$ for compressive strength, cylinders $(150 \times 300 \mathrm{~mm})$ for split tensile test, prisms $(100 \times 100 \times 500 \mathrm{~mm})$ for flexural strength, cylinders $(150 \mathrm{x}$ $300 \mathrm{~mm}$ ) for stress-strain curve with 0\% and 15\% replacement of OPC with Metakaolin for M70 grade concrete for temperature study i.e., for $100^{\circ} \mathrm{C}, 200^{\circ} \mathrm{C}, 300^{\circ} \mathrm{C}, 400^{\circ} \mathrm{C}$ and $500^{\circ} \mathrm{C}$.To cure the specimens for 28 days.

3. To evaluate the mechanical characteristics of concrete such as compressive strength, split tensile, flexural strength, stress-strain curve. 
4. To evaluate the durability studies of M70 grade Metakaolin replacement concrete with $0.5 \%$ and $1 \%$ concentrations of $\mathrm{HCl}$ and $\mathrm{H}_{2} \mathrm{SO}_{4}$.

5. To evaluate the temperature studies of $\mathrm{M} 70$ grade $\mathrm{MKC}$ at an exposure of $100^{\circ} \mathrm{C}, 200^{\circ} \mathrm{C}, 300^{\circ} \mathrm{C}, 400^{\circ} \mathrm{C}$ and $500^{\circ} \mathrm{C}$ for $1 \mathrm{hr}, 2 \mathrm{hr}$ and $3 \mathrm{hr}$ duration. To evaluate and compare the results.

\section{Results And Discussion}

The tests were carried out to obtain compressive strength, split tensile strength, flexural strength and stress-strain curve of M70 grade concrete. The specimens are tested for 28 days for $0 \%, 10 \%, 15 \%, 20 \%, 25 \%$ and 30\% replacement of MK for compressive strength and the specimens are tested for 28 days for $0 \%$ and $15 \%$ replacement of MK for flexural strength, stress-strain curve, split tensile strength. These are presented in tables and graphs were plotted correspondingly.

In the present experimental work the specimens exposed to temperature undergo physical changes and weight loss. The free moisture content is lost initially, followed by physical adsorption of water.

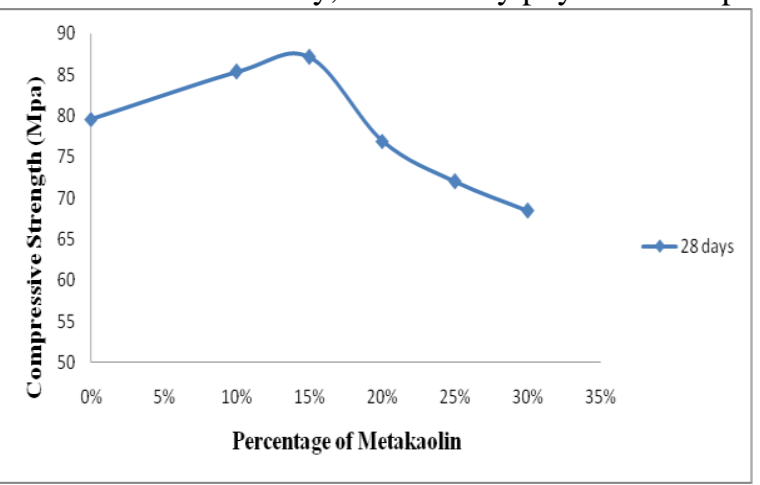

Figure 1. Compression strength of concrete vs. \% of Metakaolin

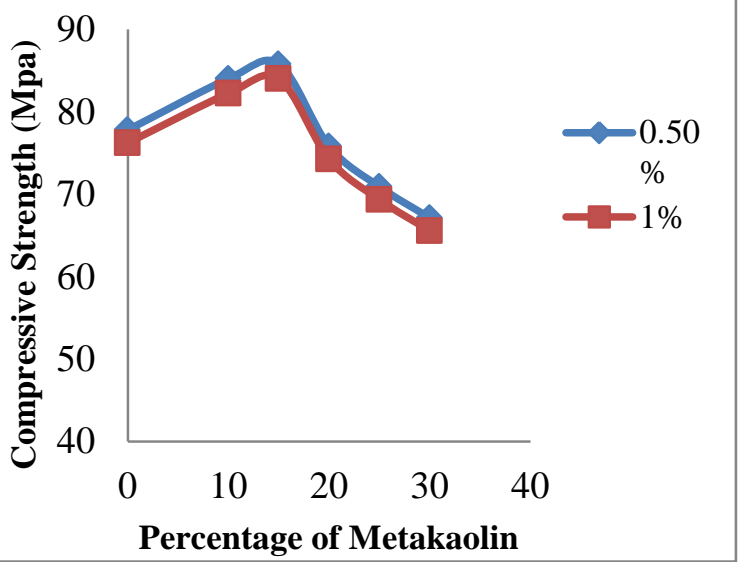

Figure 2. Compressive Strength of concrete vs. \% of $\mathrm{MK}$ at $0.5 \%$ and $1 \% \mathrm{HCl}$

From the above Fig: 2 , it is observed that at $15 \%$ replacement of cement with MK, concrete attains maximum compressive strength when exposed to $0.5 \%, 1 \% \mathrm{HCl}$ at the age of 28 days. When the replacement exceeds $20 \%$, the compressive strength is found to be decreasing slightly.

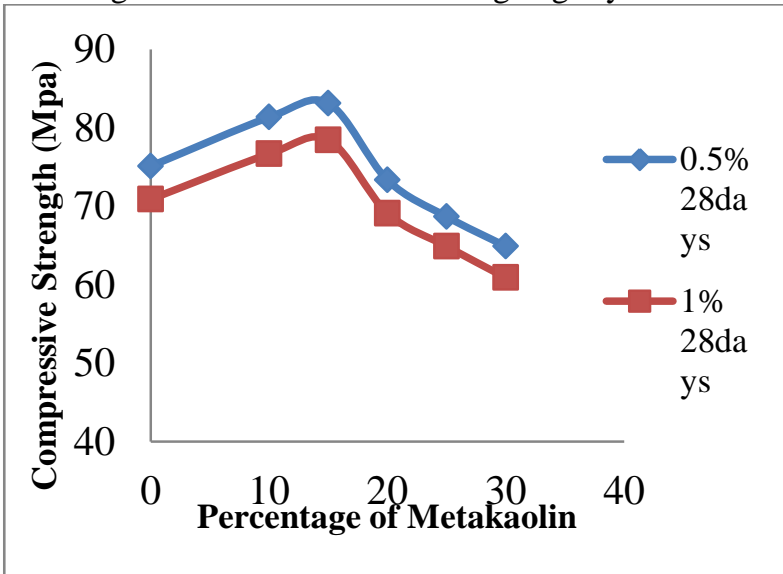

Figure 3. Compressive Strength of concrete vs. \% of Metakaolin at 0.5\%, $1 \% \mathrm{H}_{2} \mathrm{SO}_{4}$ 
From the above graph 3, it is observed that at $15 \%$ replacement of cement with MK, concrete attains maximum compressive strength when exposed to $0.5 \%, 1 \% \mathrm{H}_{2} \mathrm{SO}_{4}$ at the age of 28 days. When the replacement exceeds $20 \%$, the compressive strength is found to be decreasing slightly.

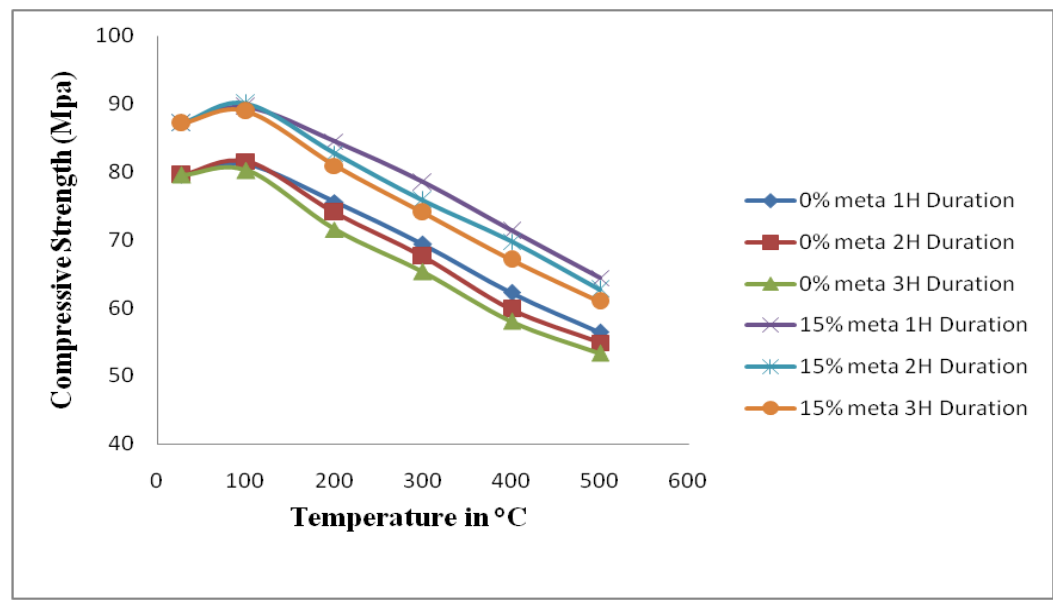

Figure 4. 28 Days Compressive Strength of concrete (\%) vs. Exposed temperature $\left({ }^{\circ} \mathrm{C}\right)$ of $0 \%$ and $15 \% \mathrm{MKC}$

From the above graph 4 , it is observed that the compressive strength increases at $100^{\circ} \mathrm{C}$ temperature when compared to the strength obtained at normal room temperature for $0 \%$ and $15 \%$ replacement of MK. The increase in compressive strength associated with the increase in temperature is attributed to the increase in the surface forces between gel particles (Vander wall forces) due to the removal of moisture content. The compressive strength decreases from $100^{\circ} \mathrm{C}$ to $200^{\circ} \mathrm{C}$ and further decreases at $500^{\circ} \mathrm{C}$.

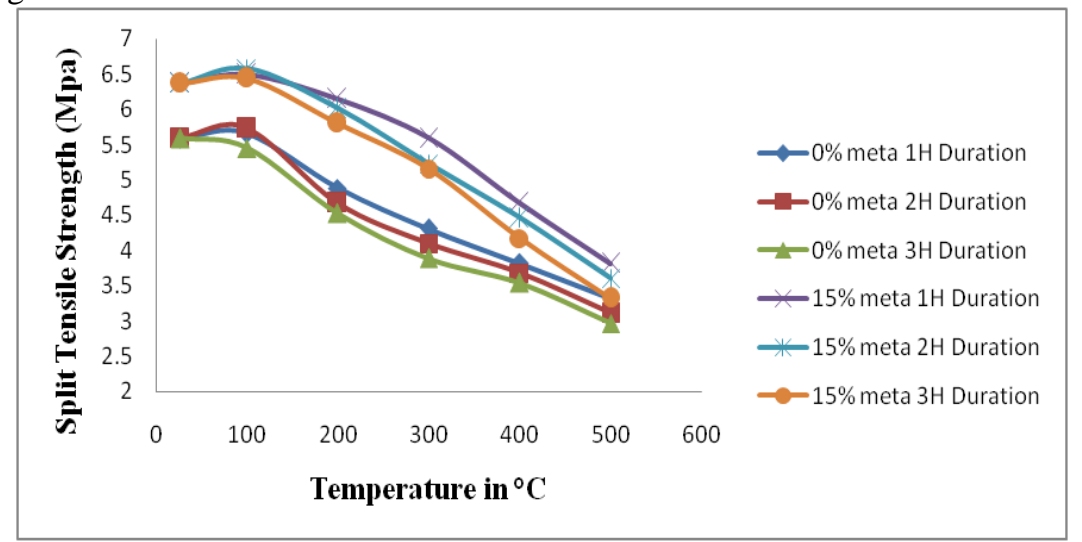

Figure 5. 28 Days Split Tensile Strength of concrete (\%) vs. Exposed Temperature $\left({ }^{\circ} \mathrm{C}\right)$ of $0 \%$ and $15 \% \mathrm{MKC}$

From the above graph 5 , it is observed that the split tensile strength increases at $100^{\circ} \mathrm{C}$ temperature when compared to the strength obtained at normal room temperature for $0 \%$ and $15 \%$ replacement of MK. The increase in split tensile strength associated with the increase in temperature is attributed to the increase in the surface forces between gel particles (Vander wall forces) due to the removal of moisture content.

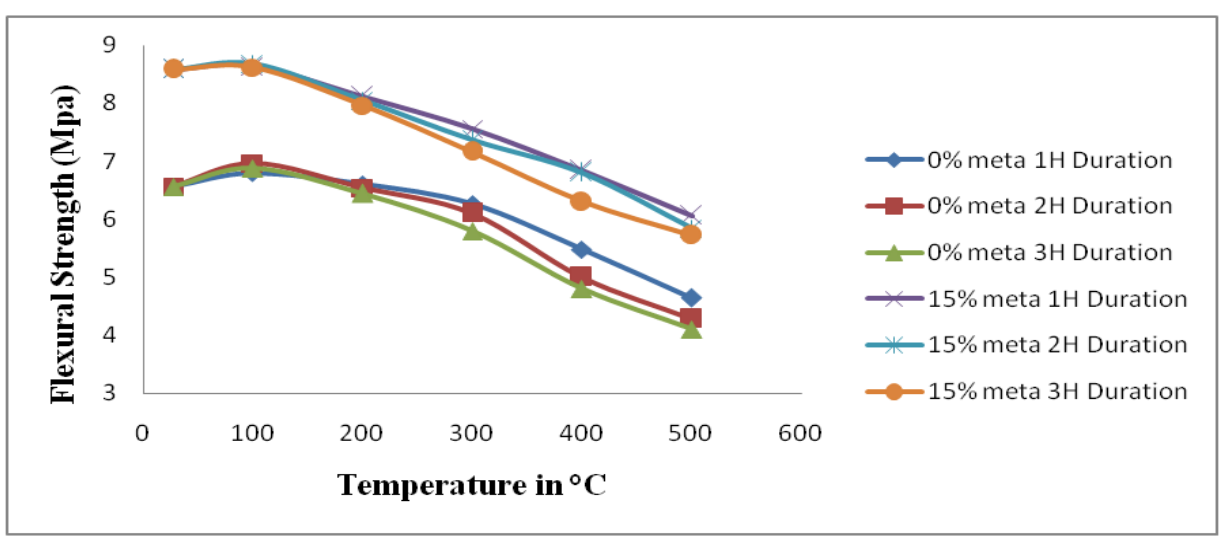

Figure 6. 28 Days Flexural Strength of concrete (\%) vs. Exposed Temperature $\left({ }^{\circ} \mathrm{C}\right)$ of $0 \%$ and $15 \% \mathrm{MKC}$ 
From the above graph 6 , it is observed that the flexural strength increases at $100^{\circ} \mathrm{C}$ temperature when compared to the strength obtained at normal room temperature for $0 \%$ and $15 \%$ replacement of MK. The increase in flexural strength associated with the increase in temperature is attributed to the increase in the surface forces between gel particles (Vander wall forces) due to the removal of moisture content.

The stress-strain behavior of cylinder specimens for $0 \%$ and $15 \%$ of metakaolin cured for 28 days age and subjected to elevated temperature from 100 to $500^{\circ} \mathrm{C}$ apart from room temperature were as shown below. The various graphs plotted are as shown in Fig. 7 to 12 .

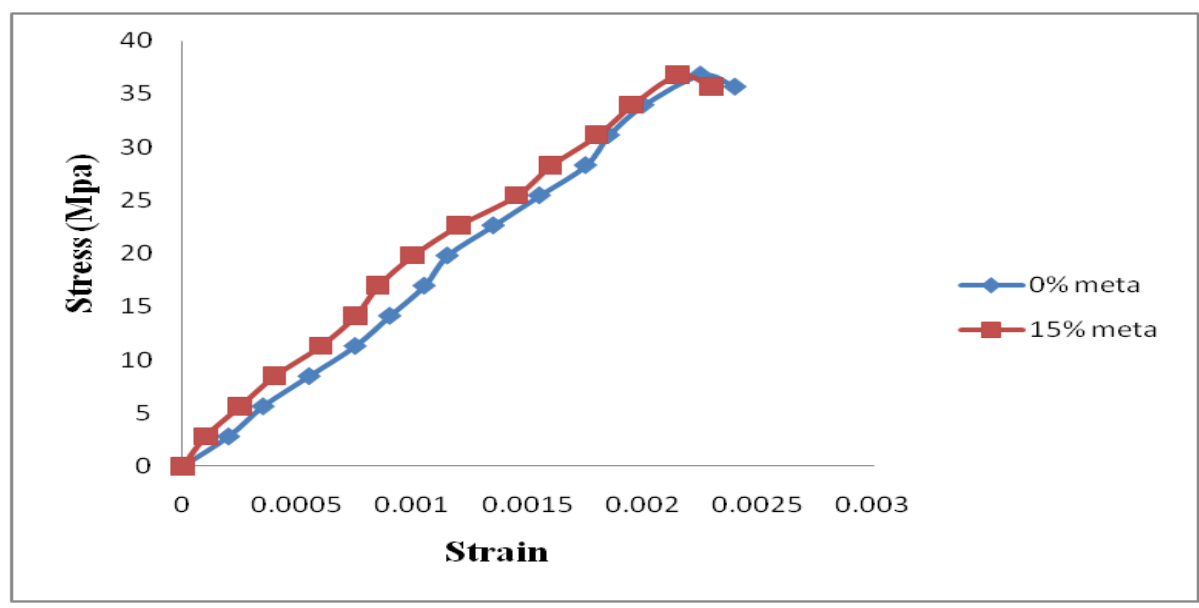

Figure 7. Stress-strain curve of concrete at room temperature

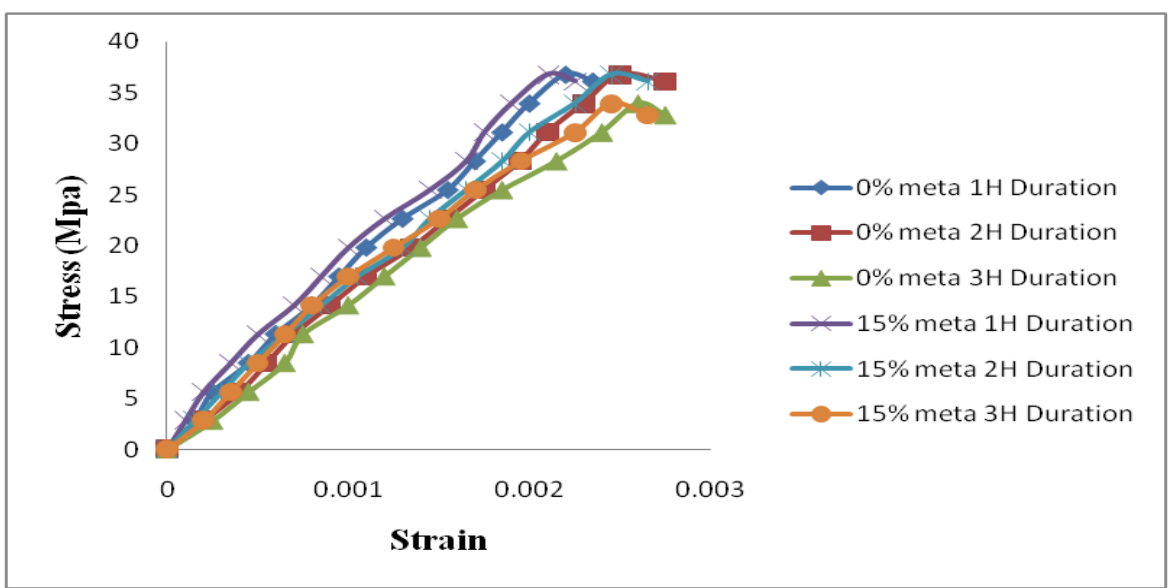

Figure 8. Stress-strain curve of concrete exposed to $100^{\circ} \mathrm{C}$ for different exposure durations

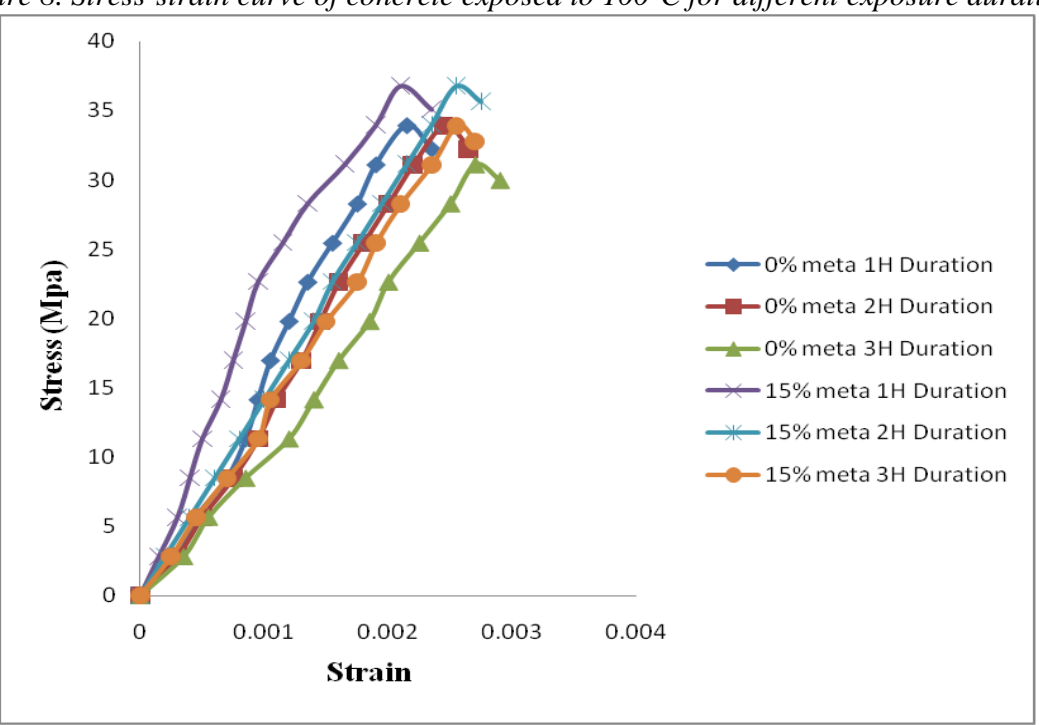

Figure 9. Stress-strain curve of concrete exposed to $200^{\circ} \mathrm{C}$ for different exposure durations 


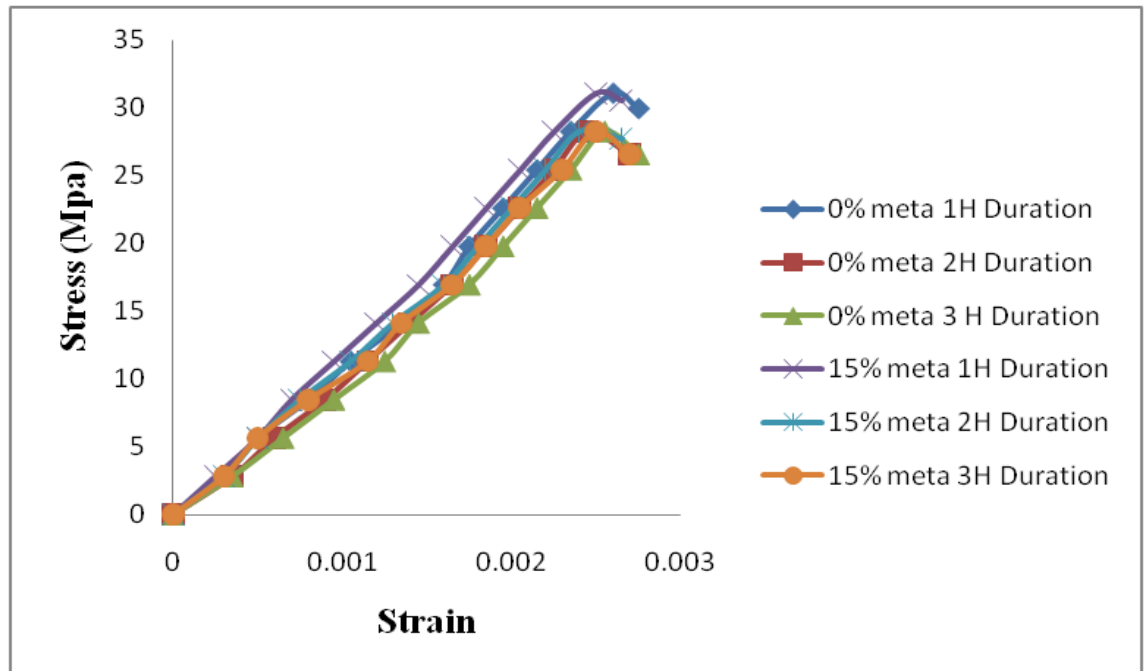

Figure 10. Stress-strain curve of concrete exposed to $300^{\circ} \mathrm{C}$ for different exposure durations

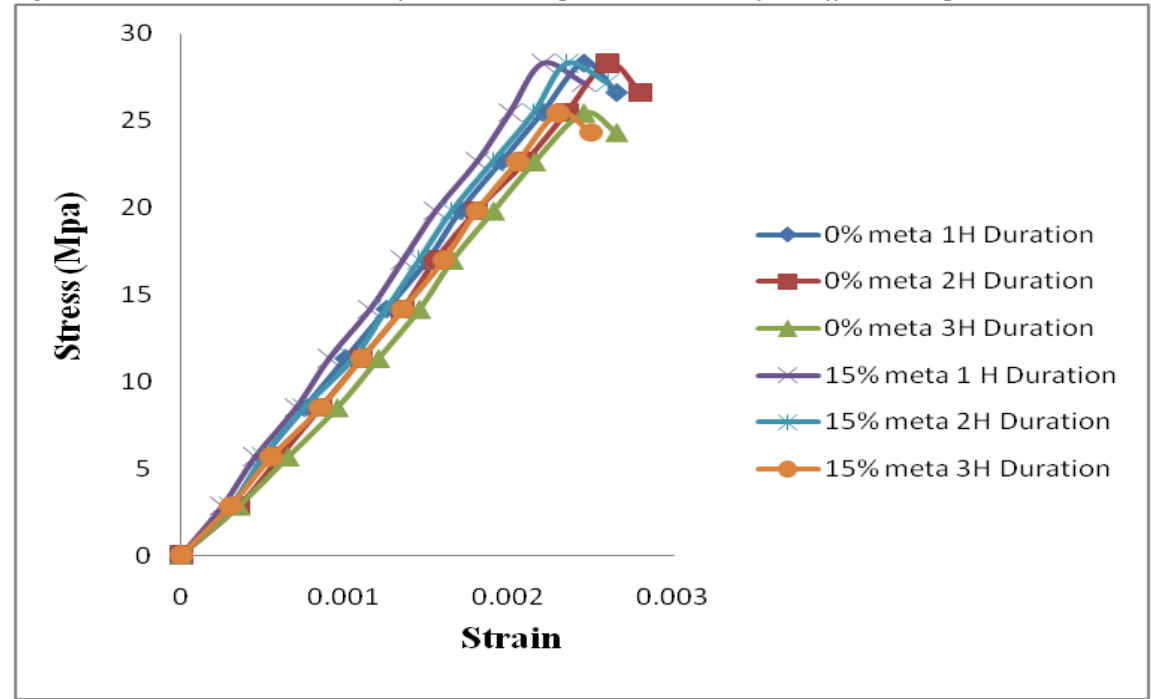

Figure 11. Stress-strain curve of concrete exposed to $400 \circ C$ for different exposure durations

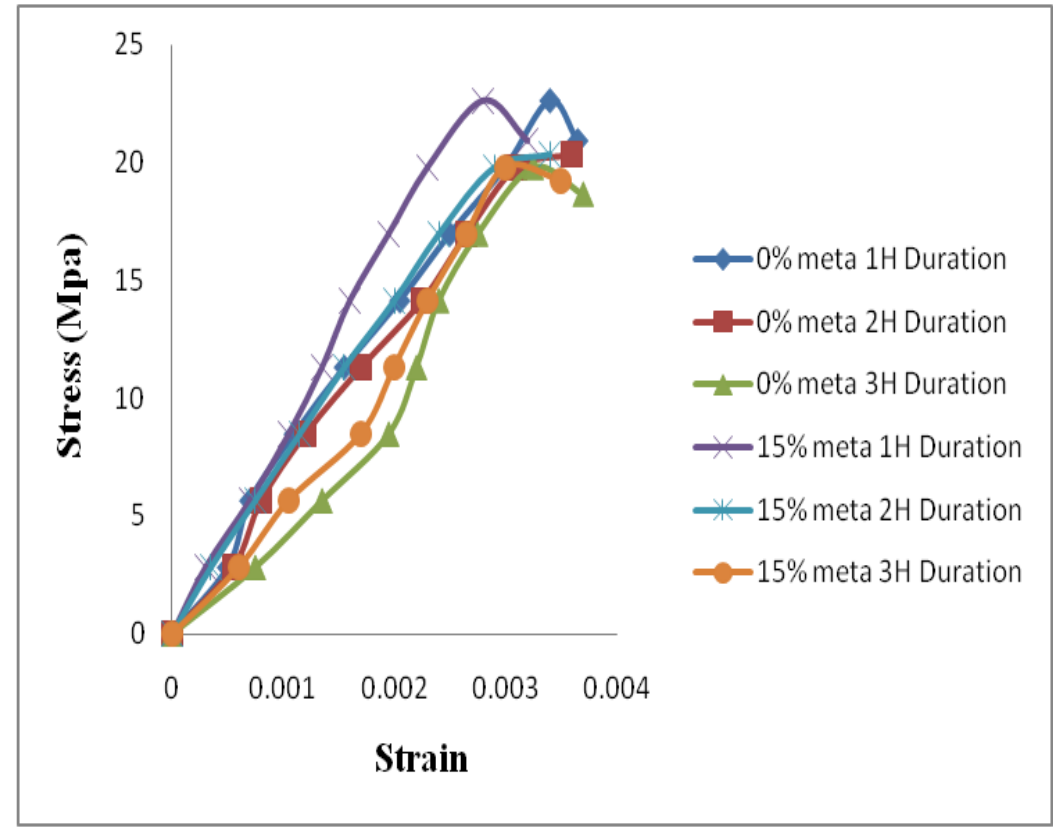

Figure 12. Stress-strain curve of concrete exposed to $500^{\circ} \mathrm{C}$ for different exposure durations 


\section{Conclusions}

Based on the experimental investigation carried out, the following conclusions are made.

1. Workability of concrete decreases with the increase in Metakaolin replacement level.

2. The compressive strength, flexure strength and split tensile strength of conventional concrete and concrete with MK as partial replacements are compared and observed and concluded that the strength of the conventional concrete is slightly lower than the MKC.

3. The compressive strength of concrete is increased when cement is replaced with Metakaolin. The compressive strength is maximum at $15 \%$ of replacement.

4. The split tensile strength of concrete is increased when cement is replaced with Metakaolin. The split tensile strength is maximum at $15 \%$ of replacement.

5. The flexure strength of concrete is increased when cement is replaced with Metakaolin. The flexure strength is maximum at $15 \%$ of replacement.

6. At room temperature and $100^{\circ} \mathrm{C}$ exposure, the stress-strain relationship is similar to the conventional concrete \& MKC behavior. However the trend is different for temperature exposure of $200^{\circ} \mathrm{C}$ to $500^{\circ} \mathrm{C}$.

7. The compressive strength of concrete showed better result at $15 \%$ replacement of MK for $0.5 \%$ and $1 \%$ $\mathrm{HCl}$ at the age of 28 days of strength.

8. The compressive strength of concrete showed better result at $15 \%$ replacement of MK for $0.5 \%$ and $1 \%$ $\mathrm{H}_{2} \mathrm{SO}_{4}$ at the age of 28 days of strength.

9. The effect of $\mathrm{HCl}$ on strength of the Metakaolin concrete is lower than the effect of $\mathrm{H}_{2} \mathrm{SO}_{4}$.

10. The strength increases at $100^{\circ} \mathrm{C}$ temperature and thereafter it starts losing its strength as the temperature increases.

\section{References}

[1]. Abdul Razak (2005) "Strength estimation model for high-strength concrete incorporating metakaolin and silica fume”, Cement \& Concrete Research 35, pp 688-695.

[2]. Bamonte p (2010) "Thermal and Mechanical Properties at High Temperature of a Very High-Strength Durable Concrete" Journal of Materials in Civil Engineering ASCE, pp 545-555.

[3]. Bo Wu,Xiao-Ping Su. Hui Li and Jie Yuan (2002) "Effect of High Temperature on Residual mechanical properties of Confined and Unconfined high strength concrete", ACI-Materials journals, Vol.99, No.4, pp 231-239.

[4]. Beulah M (2012) "Effect of Replacement of Cement by Metakalion on the Properties of High Performance Concrete Subjected to Hydrochloric Acid Attack",IJERA, Vol.2, Issue 6, pp.033-038.

[5]. Chi-Sun Poon (2003) "Performance of metakaolin concrete at elevated temperatures", Cement \& Concrete Research 25, pp 83-89.

[6]. Chi-Sun Poon (2006) "Compressive strength, chloride diffusivity and pore structure of high performance metakaolin and silica fume concrete", Cement \& Concrete Research 20 pp 858-865.

[7]. Dinakar P (2011)“High reactive metakaolin for high strength and high performance concrete" The Indian Concrete Journal, pp 2834.

[8]. Frias M (2000)“Pore size distribution and degree of hydration ofMetakaolin-cement pastes”, Cement \& Concrete Research Vol.30, pp 561-569.

[9]. IS 516: 1959, "Method of test for strength of concrete", Bureau of Indian Standards, New Delhi.

[10]. IS 12269: 1987, "Specification for 43 Grade Ordinary Portland Cement", Bureau of Indian Standards, New Delhi.

[11]. Khatib and S.Wild(1996) "Pore size distribution of Metakaolin paste" in cement and concrete research, ICJ Vol. 26 No. 10, pp 1545-1553.

[12]. Khatib and Wild(1998). "Sulphate Resistance of Metakaolin Mortar", Cement and Concrete Research, ICJ Vol .28. No. 1, pp 8392.

[13]. Long T. Phan (2000) "Fire Performance of High Strength Concrete" Journal of Materials in Civil Engineering ASCE, May 8-10.

[14]. Nabil M. Al-Akhras (2006) "Durability of metakaolin concrete to sulfate attack", Cement and Concrete Research 36, pp- 17271734.

[15]. $\quad$ Rama Rao G.V, Seshagiri Rao M.V. (1997), "Improvement in Durability Characteristics of concrete using Pozzolanic Material as Admixture", Proceedings of International Conference on maintenance \& Durability of Concrete Structures, Mar 4-6.

[16]. Rafat Siddique (2010) "Effect of metakaolin on the near surface characteristic of concrete", Materials and Structures 44, pp 77-88.

[17]. Shetty, M.S. "Concrete Technology", S.Chand\& company ltd, New Delhi.

[18]. Srinivasa Rao K, PothaRaju.M\&Raju.P.S.N (2004) "Effect of Age on HSC on Reswidual Compressive Strength under Elevated temperatures", International Conference on Advances in Concrete and Construction, pp 733-741.

[19]. Vikas Srivastava (2012)“Effect of Silica Fume and Metakaolin combination on concrete”, IJCSE, Vol.2, Issue 3, PP 893-898.

[20]. Xia oquian and Zongjinli(2001). "The relationships between stress and strain for high performance concrete with Metakaolin", Cement \& concrete research 31, pp1607-1611. 